\title{
Evaluation of Dental Composite Resin Interface and Adhesion Using Laser Scanning Confocal Microscopy
}

\author{
ADRIAN TUDOR STAN ${ }^{1 *}$, ADRIAN VADUVA ${ }^{2}$, MEDA LAVINIA NEGRUTIU ${ }^{1}$, COSMIN SINESCU ${ }^{1 *}$, CAMELIA SZUHANEK ${ }^{1 *}$, \\ ALEXANDRU ROGOBETE ${ }^{2}$, DANINA MUNTEAN ${ }^{2,3}$, SERBAN TALPOS ${ }^{1}$, VIRGIL FLORIN DUMA ${ }^{4,5 *}$, LAURA IDORASI ${ }^{1}$, \\ TAREQ HAJ AJ ${ }^{1}$, MIHAI ROMINU ${ }^{1}$ \\ ${ }^{1}$ Victor Babes University of Medicine and Pharmacy of Timisoara, Faculty of Dental Medicine, 2 Eftimie Murgu Sq., 300041, \\ Timisoara, Romania \\ ${ }^{2}$ Victor Babes University of Medicine and Pharmacy of Timisoara, Faculty of Medicine, 2 Eftimie Murgu Sq., 300041, Timisoara, \\ Romania \\ 3 Victor Babes University of Medicine and Pharmacy of Timisoara,Center for Translational Research and Systems Medicine, \\ 2 Eftimie Murgu Sq., 300041, Timisoara, Romania \\ ${ }^{4} 30 \mathrm{M}$ Optomechatronics Group, Faculty of Engineering, Aurel Vlaicu University of Arad, 77 Revolutiei Av., 310130 Arad, Romania \\ ${ }^{5}$ Politehnica University of Timisoara, Faculty of Mechanical Engineering, 1 Mihai Viteazu Av., 300006, Timisoara, Romania
}

\begin{abstract}
The aim of the study was to evaluate and to compare the interface and marginal leakage of dental composite resins using confocal laser scanning biological microscopy $(C M)$. Ten class II cavities were prepared on the proximal surfaces of 10 extracted teeth, previously kept in 10\% formalin to preserve the bonding properties of the tooth structures. Cavities were restored with dental composite resin using the 'open sandwich' technique and then assessed using CM. Open marginal adaptations at the interfaces inside the composite resins were identified. The results obtained with $\mathrm{CM}$ helped to eliminate and reduce the background information collected from a distance from the focal plane and allowed for the acquisition of serial optical sections from thick tooth specimens. In vitro assessments were thus made using CM on the teeth structure, regarding the occurrence of potential micro-leakages at the restoration interface.
\end{abstract}

Keywords: dental interface, adhesion, dental composite, polymers, confocal microscopy

With the advancement of adhesive technologies, resinbased dental composites (RBDC) have been largely used in restorative dental medicine. Nevertheless, the deficiency of composite restorations is still being disclosed in clinical investigations with a rate ranging between 6 and $50 \%$ during an investigation period of 5-17 years [1,2].

The failure of a dental composite resin is often the result of degradation mechanisms taking place within the matrix of the polymer and the silanized filler particles of the composite, as well as at the interface layer where the adhesion takes place. The degradation processes are complex and could be due to wear, abrasion, and/or fatigue $[1,3]$. When a composite restoration fails as a result of discoloration, gaps, micro-leakage at the margins, delamination, or simply due to fractures within the composite, the restoration needs to be replaced [4-6]. Thus, the most prevalent procedure experienced in daily clinical practice is the total replacement of restorations. However, this approach may be regarded as over-treatment when large portions of restorations are clinically and radiographically considered free of failures. Moreover, complete removal of a failed restoration would, generally, entail removal of enamel and/or dentin, thus leading to an important loss of sound dental tissues that could inevitably result in the weakening of the tooth or in injuries to the pulp [4]. In such cases, repair actions would preserve the tooth, as it is often difficult to remove a tooth-colored adhesive restoration without removing an integral part of the tooth.

The method employed in this study for the investigation of dental issues is confocal laser scanning microscopy, usually named simply confocal microscopy (CM). This technique has numerous advantages as compared to conventional optical microscopy, including the shallow depth of field, the elimination of out-of-focus glare, and the possibility to collect optical sections in a serial mode from thick specimens. In the biomedical field, a major application of CM involves the imaging of fixed or living cells and tissues that have been stained with one or more fluorescent dyes $[7,8]$. However, in recent years, it has been also used as an imaging method for the dental hard tissue without using the dying technique.

In particular, CM provides an improvement in marginal viewing in both axial and lateral resolution, but it is the capability of such a microscope to exclude from the image the out-of focus flare occurring in very thick samples stained with fluorochromes thathas determined the recent boom of popularity of the technique.

In the field of dentistry, the applications of CM vary from the study of the surface of enamel, dentin, and cementum to the analysis of the osseointegration and even to the visualization of cementocytes [7-9]. This is related to the fact that optical surface texture quantification and characterization of dental hard tissues are becoming increasingly used in dental medicine as a method for detecting and measuring early hard tissue damage which can result from abrasion, attrition, and dental erosion $[13,14]$. When quantifying the micro-texture of enamel surface damage, the earliest designations of wear occur at the scale of an enamel prism. Accordingly, recent research into nanometer scale surface changes of polished human enamel using CM concluded that the optimal characterization of acid mediated surface texture changes requires surface metrology instrumentation with an appropriate lateral resolution [15-19]. 
Working on this research avenue, the aim of the present study was to evaluate and compare the interface, the marginal integrity, as well as possible gaps of dental composite resins by using the $\mathrm{CM}$ technique.

\section{Experimental part}

\section{Material and methods}

Ten class II cavities were prepared on the proximal surfaces of 10 teeth that were selected from a pool of extracted human permanent teeth and were graded by two examiners from the Departments of Dental Materials and Odontology according to the International Caries Detection and Assessment System (ICDAS). The specimens were previously kept in 10\% formalin to preserve the bonding capacity of the hard tooth tissues. The teeth were carefully cleaned and polished using a rotating brush and paste (Clean Polish; Kerr Corporation) to remove the plaque, detritus, and other surface remains.

Teeth were etched with $37 \%$ ortophosphoric acid gel (Blue etch, GDF). The etchant was rubbed within the prepared cavity using a brush with soft bristles. Teeth were rinsed for $45 \mathrm{~s}$ and then dried with oil-free compressed air for $15 \mathrm{~s}$. A bonding agent (Blue Bond, GDF) was applied to the cavities restored with the dental composite. It was followed by a 60 s light curing procedure for the composite resin. The specimens were subjected to water storage (at $37^{\circ} \mathrm{C}$, for $72 \mathrm{~h}$ ) and then to thermocycling (1000 cycles, from 5 to $55^{\circ} \mathrm{C}$ ).

The specimens were analyzed using a laser scanning confocal microscope (Olympus FLUOVIEW FV1000) (fig. 1), with a 10x magnification: the width of the slices varied between 10 and $25 \mu \mathrm{m}$, while the resolution was $1020 \times$ 1024. The exposure time per pixel was $8 \mu \mathrm{s}$ and the laser wavelength was set at $405 \mathrm{~nm}$; this wavelength corresponds to a blue light laser, which was found to be appropriate for the hard dental tissues and composite resins. To picture the complete interface system, multiple images were combined using a graphical software (Icy, Quantitative Image Analysis Unit - Pasteur Institute) [7-9].

The positioning of a sample for CM imaging is shown in figure 2, pointing out the type of dental interface that is studied in this work.

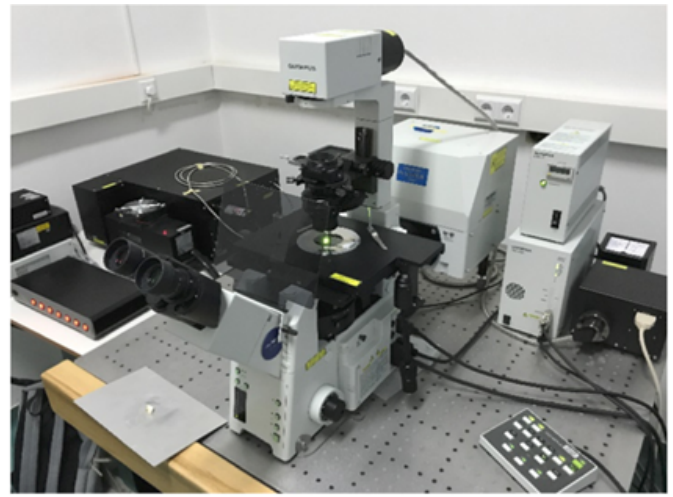

Fig. 1. Laser scanning confocal microscope (CM) Olympus Fluoview FV1000 (Laboratory for Confocal Microscopy, Center for Translational Research and Systems Medicine, Victor Babes University of Medicine and Pharmacy of Timisoara, Romania)

\section{Results and discussions}

Open marginal adaptation at the dental interfaces inside the composite resins were identified and the results obtained with CM helped to eliminate or to reduce the background information that comes from tissue that is positioned out of focus. We thus take full advantage of the

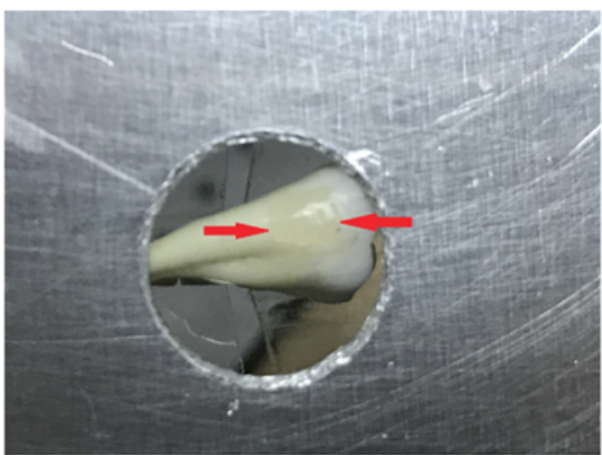

Fig. 2. Example of specimen with indicators delineating the analyzed interface observed with the $\mathrm{CM}$.

CM capability to collect serial optical sections from thick tooth specimens.

When the substrate is aged with thermocycling, bondstrength adhesion results for composite-hard dental tissue were significantly influenced by the surface conditioning method.

The CM analysis showed that the mean thickness of the resin coatings applied when restoring occurred was 10 to $15 \mu \mathrm{m}$, depending on the tested samples.

The restorative material-based gaps and the adhesion were assessed using the IBM SPSS software using sample statistics, considering images such as those shown, as examples, in figures 3 and 4.

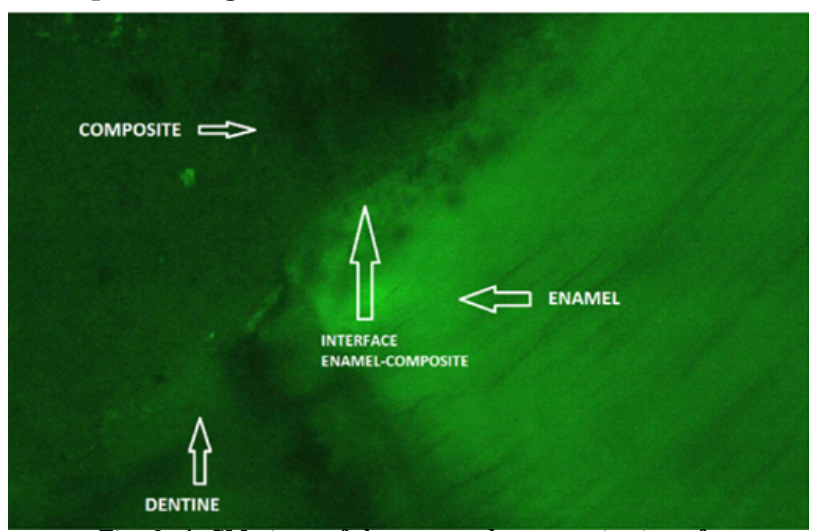

Fig. 3. A CM view of the enamel-composite interface.
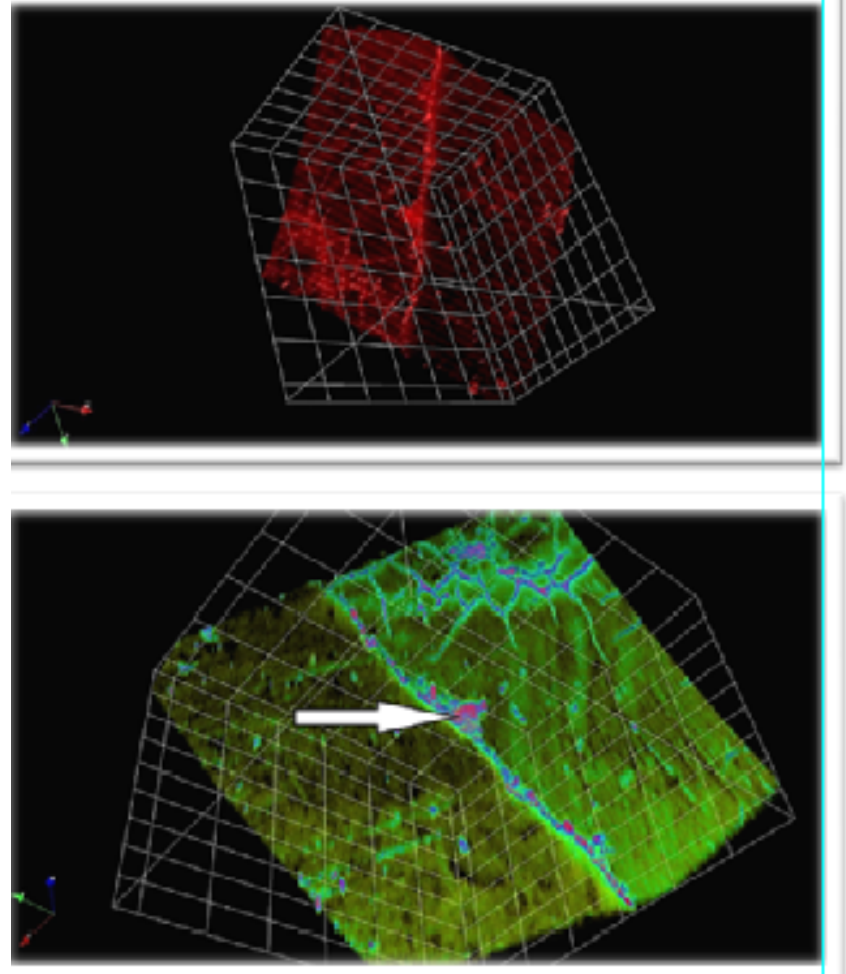


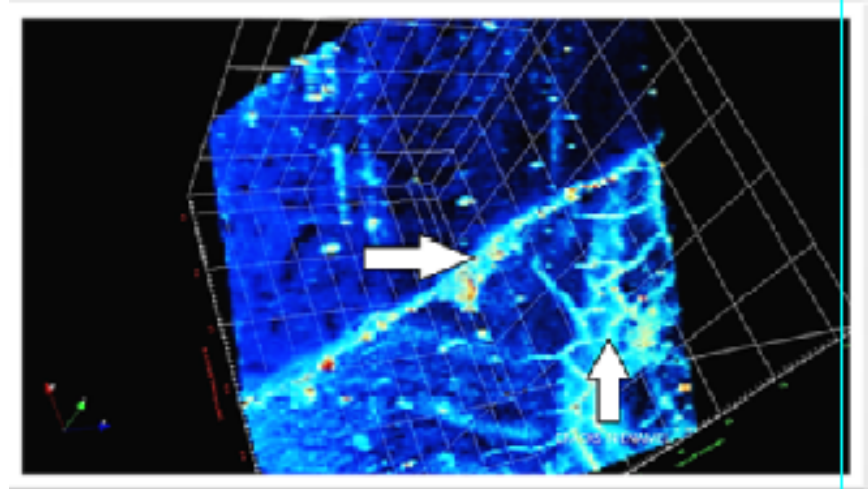

Table 1

AVERAGE VALUES (+Std.) FOR THE MARGINAL INTEGRITY ACCORDING TO THE LOCATION ( $\mu \mathrm{m})$. MEANS AND STANDARD DEVIATION STATISTICS

\begin{tabular}{|c|c|c|}
\hline & Mean & Std. Error Mean \\
\hline Mesial & 51.4000 & 9.91094 \\
\hline Occlusal $^{-}$ & 61.9000 & $8.54589^{--}$ \\
\hline Distal $^{-1}$ & 42.9000 & $5.58062^{---}$ \\
\hline Gingival $^{-}$ & 88.4000 & $6.57132^{---}$ \\
\hline
\end{tabular}

Fig. 4. Different three-dimensional (3-D) surfaces obtained with CM, showing (using white arrows) several example of defects in the material interface and cracks on the enamel surface

\begin{tabular}{|c|c|c|c|c|c|c|}
\hline & \multicolumn{6}{|c|}{ Test Value $=0$} \\
\hline & \multirow[t]{2}{*}{$\mathrm{t}$} & \multirow[t]{2}{*}{ df } & \multirow[t]{2}{*}{ Sig. (2-tailed) } & \multirow[t]{2}{*}{ Mean Difference } & \multicolumn{2}{|c|}{$\begin{array}{c}95 \% \text { Confidence Interval of the } \\
\text { Difference }\end{array}$} \\
\hline & & & & & Lower & Upper \\
\hline Mesial & 5.186 & 9 & .001 & 51.40000 & 28.9799 & 73.8201 \\
\hline Occlusal & 7.243 & 9 & .000 & $61.90000^{-}$ & 42.5679 & 81.2321 \\
\hline Distal & 7.687 & 9 & .000 & $42.90000^{-}$ & 30.2758 & 55.5242 \\
\hline Gingival $^{-}$ & -13.452 & 9 & .000 & 88.40000 & 73.5346 & 103.2654 \\
\hline
\end{tabular}

Table 2 DIFFERENTIAL STATISTICSANALYSIS
The values of the marginal discrepancy obtained for the ten considered specimens are given in Fig. 5, with the appropriate statistics. The mean values and the Standard Deviation are provided in table 1 for the four characteristic areas of the tooth: mesial, occlusal, distal, and gingival, One can remark the closer mean values obtained for the first three areas, as well as the high mean value obtained for the gingival area. The standard deviations are comparable. The statistic analysis is completed in table 2.

CM thus allows for the development of three-dimensional (3-D) images that are useful in order to evaluate the location and the magnitude of dental defects and interfaces. Using the CM technique we have pointed out numerous tooth resin filling interfaces with issues, as well as material defects inside the resin filling. Both of these can lead to micro-leakage and failure of the treatment of class I cavities. Current conventional micro-leakage test methodology uses the principle of penetration, which involves the preparation and filling of a cavity, preparation followed by the immersion of the specimen in a penetrator solution for a certain period of time. The specimen is then refined, sectioned, and examined under magnification to determine the extent and path of the infiltration. A standard benchmark is applied to determine the degree of microleakage.

In contrast to such methods, the data obtained in the present study supports the evidence that CM is a noninvasive, promising technique for dental medicine that allows for the fast detection of gaps at the restoration interface. A most useful work avenue considered in our groups is to couple CM with Optical Coherence Tomography (OCT) [20]; the latter has the supplemental capability with regard to the former to achieve a 1 to 1.5 $\mathrm{mm}$ penetration depth, with a usual 4 to 8 micrometers axial resolution [21]. Using OCT is especially attractive due to its capability to perform in vivo studies in the oral cavity using handheld scanning probes [22], with the possibility to obtain both CM and OCT images by using for example an optical chopper in the reference arm of the OCT setup. Moreover, in vivo, real-time OCT images can be achieved; thus this method of evaluation is helpful for clinical diagnostics [23- 25].

When the composite is polymerized in normal air conditions, an oxygen-inhibited surface layer is always present. This layer contains acrylate groups which do not react chemically, but are important in improving the adhesion between the substrate and the second layer by

\footnotetext{
Mean values of the marginal discrepancy for confocal laser scanning microscopy ( $\mu \mathrm{m})$
}

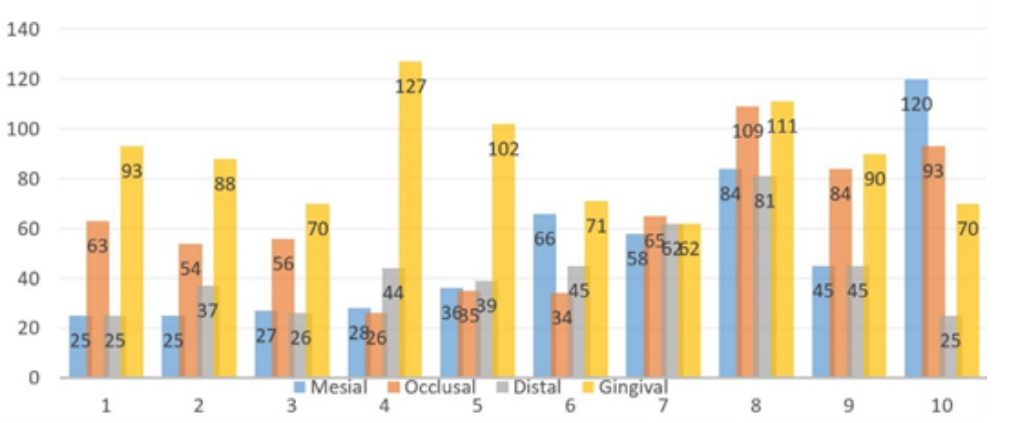

Fig. 5. The mean values of marginal discrepancy of specimens $(n=10)$ 
the formation of covalent bonds. Clinically sufficientbondstrength value may be enough, while termocycling envisions the worst case scenario for dental restorations. However, the gaps discovered by using CM cannot be ignored, and further research of the adhesion and interface layer needs to be addressed. The perspective is that, although dentists can spend more than $60 \%$ of their chairside time changing restorations, with the introduction of newer adhesives methods the lifespan of the fillings could be prolonged.

Our data are in line with the findings of Sundry studies who pointed out that the dye leakages in different sections taken at diverse places of the restorations may show important and compelling differences. For this reason, the accuracy of a leakage study based on a single section made from a tooth may not be sufficiently representative and accurate, thus being necessary another method of investigation like CM.

\section{Conclusions}

CM provides reliable information regarding the penetration and distribution of resin as compared to conventional methods like optical microscopy, and it can be systematically used for the assessment of the adhesion and gaps at the interface of composite restorations. The study utilized CM in order to make such assessments and provided data on the integrity of the enamel-composite interface.

Acknowledgements: This research was partially supported by a PhD grant of the Victor Babes University of Medicine and Pharmacy of Timisoara, no. 3811/03.10.2016 (contractno. 14828/24.10.2016), as well as by the Romanian National Authority for Scientific Research, CNDIUEFISCDI Project PN-III-P2-2.1-BG-2016-0297. Cosmin SinesCu also acknowledges the support of the Victor Babes University of Medicine and Pharmacy of Timisoara (Grant PIII-C2-PCFI (2015-2016), DENTALOCT).

\section{References}

1.P. A. DA ROSA RODOLPHO, M. S. CENCI, T. A. DONASSOLLO, A. D. LOGUERCIO, F. F. DEMARCO., A clinical evaluation of posterior composite restorations: 17-year findings. J Dent 2001, 34, 427-435.

2. R. HICKEL, J. Manhart Longevity of restorations in posterior teeth and reasons for failure, Journal Adhes Dent 2001, 3, 45-64.

3. J.-F. ROULET, Degradation of dental polymers, Basel: Karger; 1987. p. $40-52$.

4.I. A. MJøR, Placement and replacement of restorations, Oper Dent $1981,6,49-54$.

5. D. B. BOYER, K. C. CHAN, Reinhardt JW. Build-up and repair of light-cured composites: bond strength, J Dent Res 1984, 63, 12411244.

6.V. V. GORDAN, C. SHEN, J. RILEY 3RD, I. A. MJ OR, Two-year clinical evaluation of repair versus replacement of composite restorations, J Esthet Restor Dent 2006, 18, 144-153.

7.A. NURYAWAN, B.-D. PARK, Quantification of hydrolytic degradation of cured urea-formaldehyde resin adhesives using confocal laser scanning microscopy, International J ournal of Adhesion and Adhesives 2016, 74, 10.1016/j.jjadhadh.2016.12.004.

8.A. T. STAN, A. C. COJ OCARIU, et al, Marginal integrity evaluation of dental composite using optical coherence tomography, Proc. SPIE 2016, 9670, 967012.
9.F. TIMOTHY, WATSON, A. R. ATMEH, S. SAJ INI, R. J. COOK, F. FESTY, Present and future of glass-ionomers and calcium-silicate cements as bioactive materials indentistry: Biophotonics-based interfacial an analyses in health and disease, Dental Materials 2014, 30, 50-61.

10.0̈. KANIK, L. S. TURKUN, W. DASCH, In vitro abrasion of resincoated highly viscous glass ionomer cements: a confocal laser scanning microscopy study, Clin Oral Invest 2017, 21(3), 821-829.

11.C. MURDOCH-KYNCH, M. E. MCLEAN, Minimally invasive dentistry, J Am Dent Assoc 2003, 134, 87-95.

12.M. MOUSAVINASAB, I. MEYERS. Fluoride release and uptake by glass ionomer cements, compomers and giomers. J BiolSci 2009. 4. 609-616.

13.C. J. KLEVERLAAN, R. N. B. DUINEN, A. J. FEILZER, Mechanical properties of glass ionomer cements affected by curing methods, Dent Mater 2004, 20, 45-50.

14. U. LOHBAUER, Dental glass ionomer cements as permanent filling materials -properties, limitations and future trends, Materials 2010, 3, 76-96.

15. S. PARIS, J. LAUSCH, T. SELJ E, C. E. DORFER, H. MEYER-LUECKEL, Comparison of sealant and infiltrant penetration into pit and fissure caries lesions in vitro, J Dent 2014, 42, 432-438.

16] , LAUSCH, S. PARIS, T. SELJ E, C. E. DÖRFER, H. MEYER-LUECKEL, Resin infiltration of fissure caries with various techniques of pretreatment in vitro, Caries Res 2015, 49, 50-55.

17.H. ASKAR, J. LAUSCH, C. E. D

ORFER, H. MEYER-LUECKEL, S. PARIS, Penetration of micro-filled infiltrant resins into artificial caries lesions, J Dent 2015, 43, 832-838. 18.S. PARIS, K. BITTER, M. NAUMANN, C. E. DORFER, H. MEYERLUECKEL, Resin infiltration of proximal caries lesions differing in ICDAS codes, Eur J Oral Sci 2011, 119, 182-186.

19.M. OZCAN, B. KOC-DUNDAR, Composite-composite adhesion in dentistry: a systematic review and meta-analysis, J of Adhesion Science and Technology 2014, 28, 2209-2229.

20.W. DREXLER, M. LIU, A. KUMAR, T. KAMALI, A. UNTERHUBER, R. A. LEITGEB, Optical coherence tomography today: speed, contrast, and multimodality, J Biomed Opt 2014, 19, 071412.

21. S. CANJAU, C. TODEA, M. L. NEGRUTIU, C. SINESCU, F. I. TOPALA, C. MARCAUTEANU, A. MANESCU, V.-F. DUMA, A. BRADU, AND A. GH. PODOLEANU, Optical Coherence Tomography for Non-Invasive ex vivo Investigations in Dental Medicine - a Joint Group Experience (Review), Modern Technologies in Medicine 2015, 7(1), 97-115.

22.V.-F. DUMA, G. DOBRE, D. DEMIAN, R. CERNAT, C. SINESCU, F. I. TOPALA, M. L. NEGRUTIU, GH. HUTIU, A. BRADU, ANDA. GH. PODOLEANU, Handheld scanning probes for optical coherence tomography, Romanian Reports in Physics 2015, 67(4), 1346-1358.

23.C. SINESCU, M. L. NEGRUTIU, A. BRADU., V.-F. DUMA, AND A. GH. PODOLEANU, Noninvasive quantitative evaluation of the dentin layer during dental procedures using Optical Coherence Tomography, Computational and Mathematical Methods in Medicine, 2015, Paper ID 709076.

24. SZUHANEK C., GRIGORE A.- Determination of microelements from orthodontic implants by the flame atomic absorption spectroscopy method.Rev. Chim. (Bucharest), 66, no. 10, 2015 p. 1600-1602

25.SZUHANEK C., JIANU R, CIRCIUMARU L, NEGRUTIU M, SINESCU C, CLONDA C.S., SCHILLER E, POPA A, GRIGORE A-Microstructural Changes in Orthodontic Archwires after Alternative Bending Techniques. Rev. Chim. (Bucharest), 67, no. 11/2016,p.2363-2364

Manuscript received: 21.08 .2018 